\title{
Evaluation of Starch-Biopolymer Synthesized from Chaffs of Common Beans (Phaseolus Vulgaris)
}

\author{
Sunday A. Afolalu ${ }^{1}$, Omolayo M. Ikumapayi ${ }^{2}$, Abiodun A. Abioye ${ }^{1}$, Olabisi O. Yusuf ${ }^{3}$, Moses E. Emetere ${ }^{4}$ \\ ${ }^{1}$ Department of Mechanical Engineering, Covenant University, KM. 10 Idiroko Road, Canaan Land, Ota 112212, Nigeria \\ ${ }^{2}$ Department of Mechanical and Mechatronics Engineering, Afe Babalola University, Ado Ekiti 360101, Nigeria \\ ${ }^{3}$ Department of Microbiology, Obafemi Awolowo University, Ile-Ife 220282, Nigeria \\ ${ }^{4}$ Department of Physics, Covenant University, KM. 10 Idiroko Road, Canaan Land, Ota 112212, Nigeria
}

Corresponding Author Email: Ikumapayi.omolayo@abuad.edu.ng

https://doi.org/10.18280/ijdne.160509

Received: 27 April 2021

Accepted: 20 July 2021

\section{Keywords:}

LDPE, biodegradation, biocomposite, starch, potato, cassava, nanoparticles

\begin{abstract}
The resilience and resistance of plastics to decomposition have led to the imperative need to develop biodegradable plastics as a viable solution. Starch biodegradable films have been synthesized recently as a sustainable replacement for synthetic plastics. Acid hydrolysis was used to synthesize starch nanoparticles from the chaffs of Common Beans (Phaseolus vulgaris) which was mixed with varying percentages of Low-Density Polyethene (LDPE: C-S; 95:5, 90:10, 85:15, 80:20) by the heating process. Characterization of the starch nanoparticles was done using the FTIR, TEM, and EDX while the physicochemical properties (Compression, Hardness, and Biodegradation) of the produced biopolymers (LDPE-Starch) were also studied. Starch spectrum was observed at $3436 \mathrm{~cm}^{-1}$ and other functional groups such as Carbonyl group, Sulphones, and Acetylenic groups were also revealed by Fourier Transmission Infra-Red Spectroscopy. The starch nanoparticles were observed to be flake-like shapes with a size of 50nm as shown by the TEM analysis. Of all the varying compositions of starch biopolymer synthesized, 90:10LDPE/B-S had the best hardness properties with 40.78HD and constant degradation was observed within weeks 3 and 4 in 95:5 (LDPE-B.S) with a peak value of $0.7705 \%$. The study revealed the economical and sustainable production of starch nanoparticles from the chaffs of Common beans (Phaseolus vulgaris) and its use for the improvement of biodegradable plastic films.
\end{abstract}

\section{INTRODUCTION}

The threat to marine life annually is becoming challenging caused because of extreme and indiscriminate dumping of plastic waste into the ocean [1]. Plastics cannot be avoided; they are being utilized daily in many industries. A larger percentage of the plastics being utilized are synthesized from fossil fuel reserves known as "synthetic plastics" synthetic plastic production is projected to be 2.5 times higher than the 381 million tons in 2015 by 2050 [2]. The excess demand for products synthesized from these fossil reserves could lead to the exhaustion of these natural resources in the nearest future. In a bid to overcome this, scientists have shifted to the synthesis of eco-friendly packaging materials that could probably reduce dependence on fossil fuels and make use of alternative biomaterials especially starch which is broadly used. Consequently, the need for biodegradable plastics has facilitated the recent spike in the generation of sustainable alternatives for synthetic plastics [3]. The development of ephemeral bioplastics is perceived as the key goal, and it involves the use of natural and raw materials for the creation of degradable thermoplastics [4, 5]. This field is rapidly advancing to solve the plastic waste build-up issue by developing polymers that possess the ability to fragment and decompose into nonthreatening by-products in our environment [6]. Studies have synthesized starch at a nano- sized range through acid hydrolysis which gave a good result $[7,8]$. They have relatively high crystallinity, stability, and are mostly desired in the food processing industry where temperatures are high, and they have improved film properties [9]. Starch nanoparticles (SNPs) of natural origin are commonly incorporated in the polymeric matrix as fillers to improve their properties. Their production methods are quite broad and significantly influence their characteristics, such as size distribution, crystalline structure, and physical properties, amongst many others [10].

The abundance and the huge production of starch have appreciated their applications in many industries such as the food, cosmetic, pharmaceutical, and textile industries. The use of starch in these industries varies such as in the use of thickeners, stabilizers, and adhesive agents, medical delivery systems [11]. Recently, industrial application of starch has cut across into the synthesis of biodegradable plastics and nanofilms [12].

The content of starch ranges in percentage among the various plant sources and their botanical sources. It has $(60-$ $80 \%$ ) in grains such as rice, millet maize while it has (25-50\%) in legumes and some widely consumed fruits such as mango and banana $(70 \%)$ on a dry weight basis [13]. Thus, the need for an enormous quantity of starch required for its production at the commercial level has created interest in new sources like legumes and fruit kernels. Legumes are consumed all over the 
world in a variety of forms and processed differently according to the taste and cultural preferences of people [14]. Although legume has been shown to contain more proteins than grains, this has given more preferences to the application of grainstarches in several industries over the years. Major studies have been done on the properties of starches from various botanical sources of grains and tuber crops such as yam, maize, potatoes, rice $[15,16]$. However, minimal studies on the properties of legume starches have resulted in limitations in their applications in many industries.

Most leguminous plants have a starch content that ranges between $24 \%$ and $65 \%$, with different sizes, shapes (spherical or ellipsoidal), and they also have a high amount of amylose [17]. The high amylose content in legumes gives it some specific features such as high gelatination, shear-thinning resistance, rapid retrogradation, increased starch resistance, and gel elasticity [18]. The few studies derived from legumes starch give the potentials to further delve into studying some features associated with beans most especially at the nanosized level. Hence, this study synthesized starch nanoparticles from the chaff of common beans (Phaseolus vulgaris) and produced biopolymer with varying percentages of starch nanoparticles and Low-Density Polyethene which were further characterized and studied for their mechanical properties.

\section{METHODOLOGY}

\subsection{Starch extraction process}

Bean chaffs were purchased from the Sango market and transported to the Department of Mechanical Engineering, Covenant University. Dirt particles and other impurities were found within the chaffs by hand-picking and then washed the chaffs in distilled water which was later ground using an electric blender.

\subsection{Sample preparation}

\subsubsection{Starch extraction process}

After the impurities had been removed and the chaffs of Phaseolus vulgaris has been washed thoroughly with distilled water, it was then ground into a fine powder using the blender and then soaked in distilled water for 24 hours. Thereafter, the supernatant liquid (starch slurry) was filtered and allowed to settle in a tank for 40 minutes. The collected starch was then dried at $70^{\circ} \mathrm{C}$ in a dry oven for about 2 hours to ensure the release of moisture content in the starch and complete dryness and it was then sieved using a wire-mesh of $0.2 \mu \mathrm{m}$ particle size to obtain a micrometer starch particle.

\subsubsection{Synthesis of starch nanoparticles}

Acid hydrolysis was used for the synthesis of the starch nanoparticles derived from Common beans (Phaseolus vulgaris). The process is sectioned into five stages.

A. The chemical reaction of the starch nanoparticles: $73.45 \mathrm{~g}$ of the dried starch powder was transferred to a $250 \mathrm{ml}$ bottom flask followed by the addition of hydrogen peroxide whilst stirring continuously. Thereafter, $5 \mathrm{ml}$ of $2 \mathrm{M}$ sulphuric acid was poured gradually into the mixture stirring vigorously. The purpose of sulphuric Acid was to catalyze the cleavage of a chemical bond with the addition of water.
Sulphuric acid is known to be the most suitable starch hydrolyzing agent. The flask containing the mixture was placed on a hotplate stirrer revolving at $2000 \mathrm{rpm}$, and a temperature of $150^{\circ} \mathrm{C}$ for 3 days (Figure 1).

B. Centrifugation: Starch slurries obtained from the chemical reaction process was filled into $10 \mathrm{ml}$ centrifuge tubes and added up with distilled water. These were spun in a Surgifield SM-8 - 2 Centrifuge Machine (Figure 2) at $4000 \mathrm{rpm}$, for 10 minutes. The filtrate was decanted into water kegs.

C. Ultra-sonication: the filtrate was subjected to sonication using a Branson M2800HUltrasonicator for 90 minutes.

D. Oven drying: The sonicated samples were oven-dried in an oven at $140^{\circ} \mathrm{C}$

E. Manual Declustering: Separation of the starch clusters, this was done by hand.

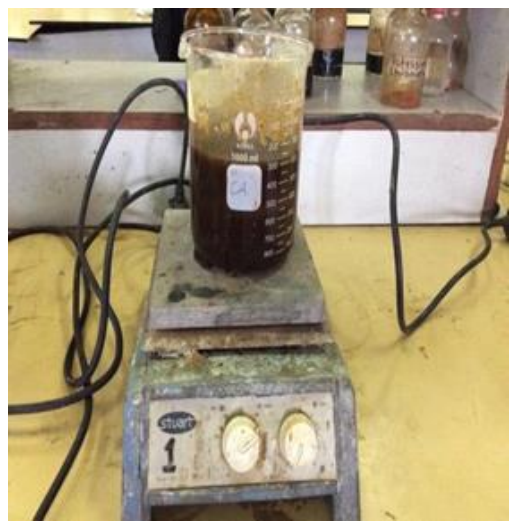

Figure 1. Acid hydrolysis set

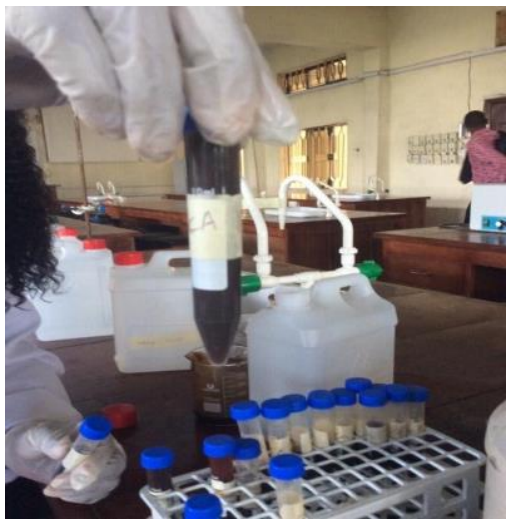

Figure 2. Centrifugation sample

\subsection{Polymer blend production}

The polymer blend was synthesized by adjusting the proportions of LDPE to starch nanoparticle/starch micro particle ratio (Table 1). The synthesized LDPE pellets were subjected to heating $\left(120^{\circ} \mathrm{C}\right)$ in a beaker till melted. Then, the starch nanoparticles were introduced into the melted LDPE and stirred mechanically. Glycerol (plasticizer) was also added to the mixture whilst the stirring continued. The mixture was poured immediately into a titanium mold and allowed to set. This procedure was also repeated for the starch microparticle. Due to the difference in starch got after cooling; it was detached and stored at room temperature. The LDPE Starch Blends are shown in Figure 3. 
Table 1. LDPE-Bean Starch (nanoparticle)/starch formation

\begin{tabular}{ccc}
\hline \multicolumn{3}{c}{ Sample NameLDPE (wt\%) Bean Starch (wt\%) } \\
\hline 5 B. S & 95 & 5 \\
10 B. S & 90 & 10 \\
15 B. S & 85 & 15 \\
20 B. S & 80 & 20 \\
\hline
\end{tabular}

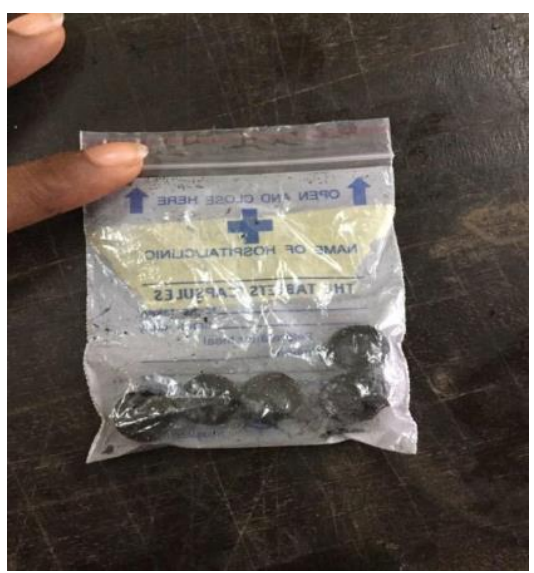

Figure 3. Produced LDPE-Starch blends

\subsection{Methods of characterization of starch nanoparticle}

Characterization of the synthesized starch nanoparticles was done using the Fourier Transform Infrared (FTIR), Transmission Electron Microscope (TEM), Energy Dispersive X-ray Spectroscopy (EDS). Mechanical properties such as hardness testing, compression test, and biodegradation study for the synthesized LDPE polymers were carried out.

\subsection{Starch nanoparticle characterization}

\subsubsection{Fourier Transform Infrared (FTIR)}

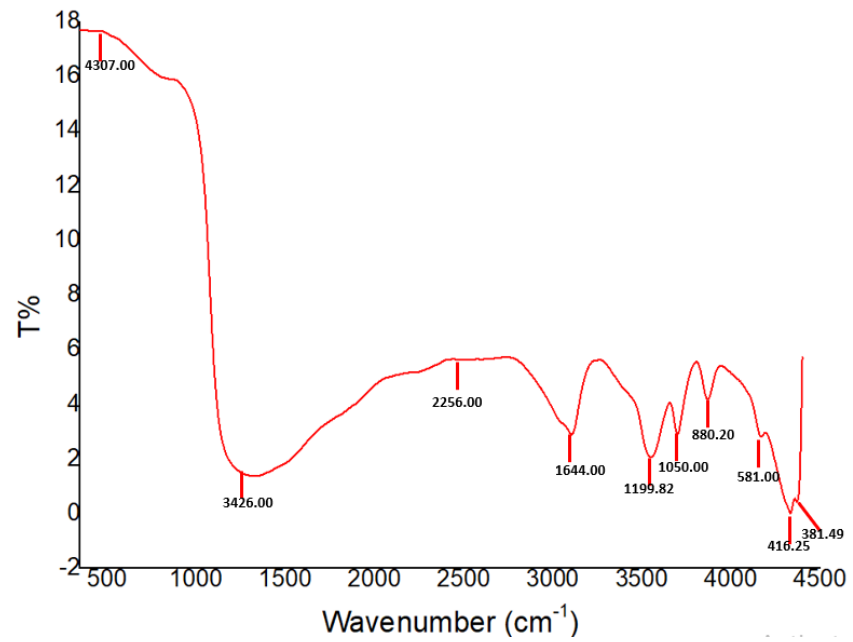

Figure 4. Infrared Structure of Starch nanoparticles Synthesized from Phaseolus vulgaris

FTIR analysis was performed using a Nicolet iS10 FTIR spectrometer for the identification of the functional groups in the starch nanoparticle samples. This involves the use of Infrared radiation for absorbance into the sample. The radiation absorbed by the sample was converted to vibrational energy producing a unique spectral representation of the molecule. The spectrum ranges between $350 \mathrm{~cm}^{-1}$ to $4000 \mathrm{~cm}^{-1}$ frequency as shown in Figure 4.

\subsubsection{Transmission Electron Microscope (TEM)}

The Jeol ARM-200F-G transmission electron microscope was used in detecting the size and morphology of the starch nanoparticles and the micrographs obtained are presented in Figures 5 and 6 for the nanoparticles synthesized from Phaseolus vulgaris and that of LDPE respectively.

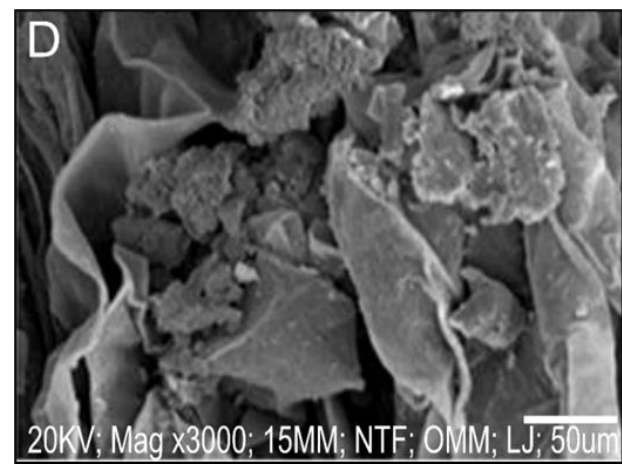

Figure 5. TEM graph of Starch nanoparticles Synthesized from Phaseolus vulgaris

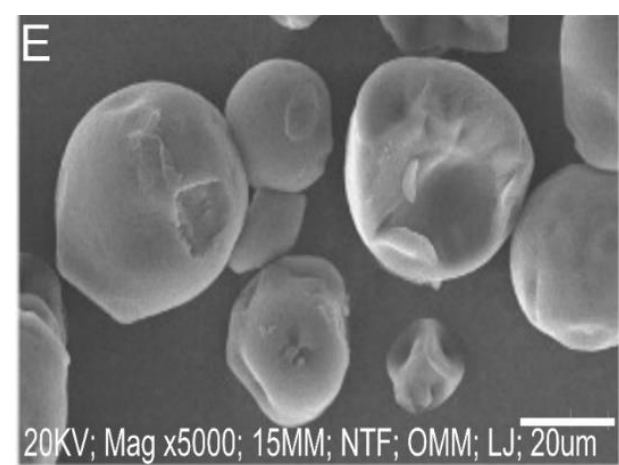

Figure 6. TEM graph of LDPE

\subsubsection{Energy Dispersive X-ray Spectroscopy (EDS)}

The JSM-7600F Schottky Field Emission Scanning Electron Microscope was used for this analysis. This was used to obtain the constituent elements of the samples. The obtained results for Phaseolus vulgaris Synthesized Starch and LDPE are depicted in Figures 7 and 8 respectively.

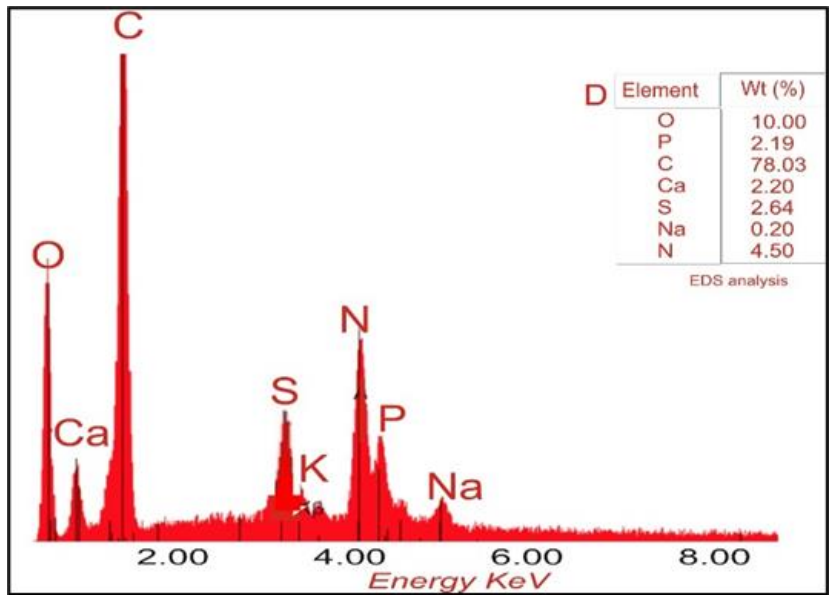

Figure 7. EDS graph of Phaseolus vulgaris synthesized starch 


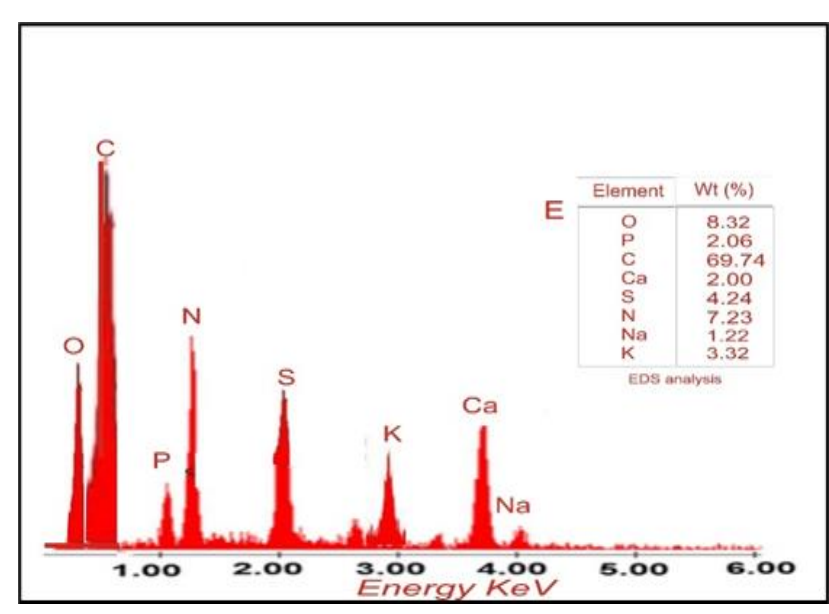

Figure 8. EDS graph of LDPE

\subsection{Hardness testing}

A shore-D hardness tester was used to test for the hardness of each synthesized LDPE starch blend sample. The samples were each placed on the sensor of the durometer with different points of the surface of the samples tested to get an average reading.

\subsection{Biodegradation study}

The soil sample was collected from the mechanical engineering garden, Covenant University into a labeled container for each of the LDPE starch blends. The biodegradation rate was studied by burying the labeled bioplastics samples (microparticle and nanoparticle) at a 4.5 inches soil depth. The initial weight of each of the bioplastics samples was taken before burial into the soil. The LDPE starch blends were exhumed, brushed, weighed, and buried back into the soil at every 7 days, this continued for 28 days. The weight was recorded and the degradation ratio for each of the samples was determined using Eq. (1).

$$
\text { Degradation Ratio }(\%)=\frac{W c-W i}{W i} \times 100
$$

where, $\mathrm{W}_{\mathrm{i}}$ represents the initial weight $(\mathrm{g}), \mathrm{W}_{\mathrm{c}}$ represents the current weight $(\mathrm{g})$.

\section{RESULTS AND DISCUSSIONS}

\subsection{Characterization of the produced starch nanoparticles}

3.1.1 Fourier Transform Infrared (FTIR) of produced nanoparticle starches

The FTIR analysis of Starch obtained from Phaseolus vulgaris revealed starch spectra at $3426 \mathrm{~cm}^{-1}$ which aligns with the $\mathrm{O}=\mathrm{H}$ stretching vibrations of hydroxyl groups which are abundant in the chemical structure of amylose and amylopectin, the main composition of starch biopolymer. This is shown in Table 2. Also, the carbonyl $(\mathrm{C}=\mathrm{O})$ stretching was at $2256 \mathrm{~cm}^{-1}$ which accounts for the formation of strong hydrogen bonds. Acetylenic C-H blend and Sulphones were also observed to be present at $581 \mathrm{~cm}^{-1}$ and $416 \mathrm{~cm}^{-1}$ wave numbers, respectively. Figure 4 represents a graph of transmittance (\%) versus wavelength $\left(\mathrm{cm}^{-1}\right)$. The peaks dictate the absorption of infrared radiation by the bean starch. The spectral of the wavelength varies from 350 to $4400 \mathrm{~cm}^{-1}$ of about ten peaks.

The extracted bean starch's FTIR showed wide range peaks at 4307.00 , and $3426.00 \mathrm{~cm}^{-1}$ indicating the existence of an $\mathrm{OH}$ group in the starch. Sharp-pointed peaks may be found at 2256 , 1644 , and $1199.82 \mathrm{~cm}^{-1}$ which can be connected to the $\mathrm{C}=\mathrm{O}$ Carbonyl group and $880 \mathrm{~cm}^{-1}$ with $-\mathrm{CH}$ bonding. The FTIR spectra in Figure 4 show C-H of acetylenic behaviour and O$\mathrm{H}$ bonds in the starch at specific wavenumbers, indicating the presence of strong bonds in the starch.

Table 2. FTIR band assignment for starch nanoparticles synthesized from Phaseolus vulgaris

\begin{tabular}{ccc}
\hline S. No & Wave Number $\left(\mathbf{c m}^{-\mathbf{1}}\right)$ & Functional Group \\
\hline 1 & 3426 & $\begin{array}{c}\text { Water of Crystallization } \\
\text { (O-H Stretching) }\end{array}$ \\
\hline 2 & 2256 & $\begin{array}{c}\text { Carbonyl }(\mathrm{C}=\mathrm{O} \\
\text { Stretching) }\end{array}$ \\
\hline 3 & 1644 & $\begin{array}{c}\text { Carbonyl }(\mathrm{C}=\mathrm{O} \\
\text { Stretching) }\end{array}$ \\
\hline 4 & 1199.82 & $\mathrm{C}=\mathrm{O}$ Stretching Vibration \\
\hline 5 & 1050 & $\begin{array}{c}\text { C-OH Stretching } \\
\text { Vibration }\end{array}$ \\
\hline 6 & 880.20 & -CH bonding \\
\hline 7 & 581 & Acetylenic C-H bend \\
\hline 8 & 416.25 & $\begin{array}{c}\text { Sulphones (S=O } \\
\text { stretching) }\end{array}$ \\
\hline
\end{tabular}

A flake-like shape of the nanoparticles which is confirmed by the particle size of $50 \mu \mathrm{m}$ was observed in the morphological analysis of nano starch produced from Phaseolus vulgaris (Figure 5) which must have occurred due to the bonding force in the Phaseolus vulgaris as a result of the accumulation of starch present. The controlled acid hydrolysis treatment of starch content breaks the multiscale structure of starch granules, which consists of alternating crystalline and amorphous concentric layers, releasing crystalline flake-like particles of nanoscale dimensions while that of the low-density polyethylene (LDPE) had a nodular and clustered shape at its nanoparticle size of $20 \mu \mathrm{m}$ as shown in Figure 6 above. However, bean starch has mostly been reported to be roundshaped $[19,20]$.

3.1.2 Energy-dispersive X-ray spectroscopy of produced nano-particle starches

The analysis of LDPE-starch Beans Blends (See Figure 7) was found to contain Carbon as its major element (78.03\%) and other elements such as Calcium (2.2\%), Sulphur (2.64\%), Sodium $(0.2 \%)$, and Nitrogen as its trace elements (4.5\%). Pure LDPE had elemental Carbon at (69.74\%) and other elements which include Calcium (2\%), Sulphur (4.24\%), Nitrogen (7.23\%), Sulphur (1.22\%), and Potassium (3.32\%).

\subsubsection{Biodegradation analysis}

The samples were then consequently weighed, and the new weight was recorded. The weight values across the burial period can be found in Table 3 .

From Figure 9, it was observed that 90\%-LDPE/10\%-B.SN and $80 \%$-LDPE/20\%-B.SN showed minute degradation rates throughout the 4 -week burial period with peak values $0.1487 \%$ and $0.1631 \%$ respectively. While at $85 \%$-LDPE/ $15 \%$-B.S experienced maximum degradation between week 1-2 with a peak value of $0.3372 \%$ after which degradation rate became almost constant till the end of the 4 week burial period. At 
95\%-LDPE/5\%-B.S exhibited the highest degradation rate between weeks 3-4 burial period with a peak value of $0.7705 \%$ leaving $99.23 \%$ of initial weight residue.

Table 3. LDPE/Bean starch blend (nanoparticle) biodegradation

\begin{tabular}{ccccc}
\hline \hline \multirow{2}{*}{ Period } & \multicolumn{4}{c}{ LDPE (wt.\%) } \\
\cline { 2 - 5 } & 95 & \multicolumn{4}{c}{ Weight(g) } & 80 \\
\cline { 2 - 5 } & 95 & 85 & 0.8586 \\
\hline \hline Initial & 0.7398 & 0.7395 & 0.5931 & 0.8586 \\
Week 1 & 0.7393 & 0.7391 & 0.5921 & 0.8583 \\
Week 2 & 0.7390 & 0.7389 & 0.5911 & 0.8581 \\
Week 3 & 0.7350 & 0.7387 & 0.5905 & 0.8576 \\
Week 4 & 0.7341 & 0.7384 & 0.5901 & 0.8572 \\
\hline \hline
\end{tabular}

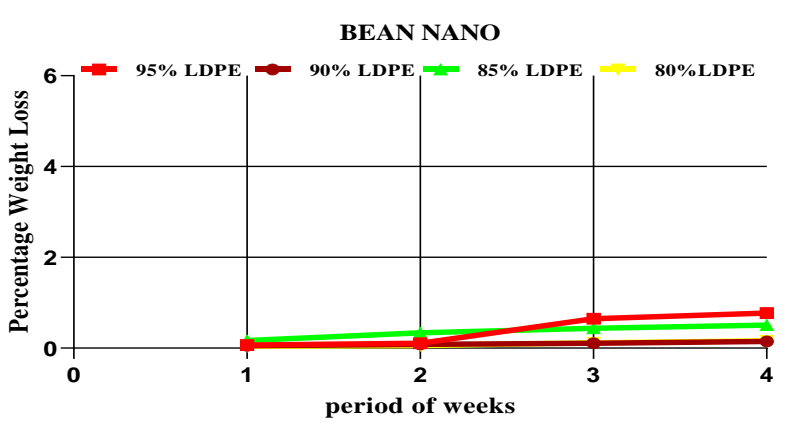

Figure 9. Effect of biodegradation on LDPE/Bean nano blend samples

3.1.4 Mechanical properties characterization result of produced polymer blends

Hardness Results. The hardness test for the average shore$\mathrm{D}$ hardness of the $100 \%$ pure LDPE was found to be 48HD as depicted in Figure 10, which falls within the standard range values for LDPE shore-D hardness stated in the Handbook of Polymers written by Wypych, (2016). The Shore D hardness of sample composition of 90 LDPE: 10 Bean starch was 40.78 has presented in Table 4 which falls within the range of the average Shore D Hardness (Wypych, 2016). Other hardness values at different compositions are presented in Table 4.

Table 4. LDPE/Bean starch (nanoparticle) blend harness

\begin{tabular}{cccc}
\hline \multicolumn{4}{c}{ Average Hardness (HD) } \\
\hline Sample & Composition (LDPE/Starch) \\
\hline $\mathbf{9 5 / 5}$ & $\mathbf{9 0 / 1 0}$ & $\mathbf{8 5 / 1 5}$ & $\mathbf{8 0 / 2 0}$ \\
27.78 & 40.78 & 34.06 & 37.36 \\
\hline
\end{tabular}

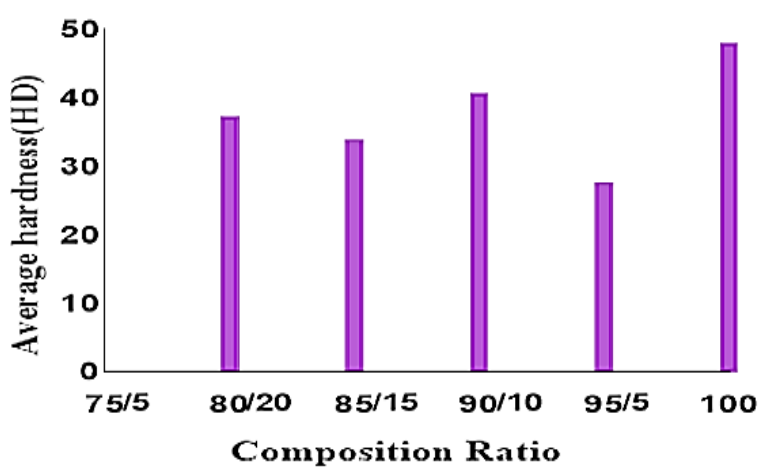

Figure 10. Compression Analysis of LDPE/B.S Blends
The graph in Figure 11 depicts that the blend that exhibited the highest maximum compressive stress amongst the blends prepared from the various LDPE/B.S starch composition ratios was the blend containing $10 \mathrm{wt} \%$ of B.S with a recording a value $4.85 \mathrm{MPa}$. The sample containing $20 \mathrm{wt} \%$ of $\mathrm{B} . \mathrm{S}$ recorded the lowest maximum compressive stress amongst all the samples produced in this research, with a value of $1.95 \mathrm{MPa}$ when subjected to a load of $229 \mathrm{~N}$. Maximum compressive stresses of $3.99 \mathrm{MPa}$ and $2.17 \mathrm{MPa}$ were recorded for samples containing $10 \mathrm{wt} \%$ and $15 \mathrm{wt} \%$ B.S.

\section{Compression Analysis of LDPE/B.S Blends}

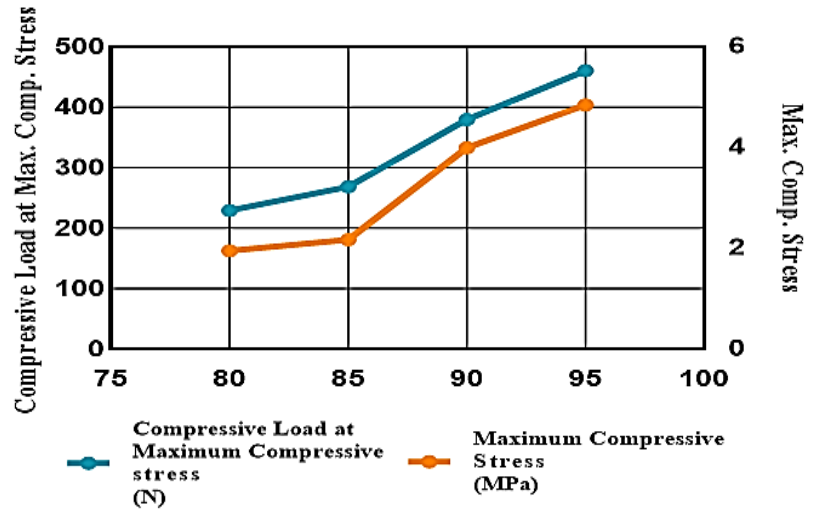

Figure 11. Comparison of Average Hardness of LDPE with LDPE/B.S Samples

\section{CONCLUSIONS}

The advantages in the use of starch nanoparticles synthesized from agricultural foods for bioplastics synthesis are getting quite interesting and the replacement in petroleumbased plastics is turning into more possibilities. However, to support food 8circulation, there is a diversion into the use of agro-waste products which is more economical and available. Starch nanoparticles were synthesized from the chaffs of beans and further characterized. The starch nanoparticles were used to produce Low-Density Polyethene-starch blends (LDPE/Starch Blends) which were assessed for their mechanical properties such as hardness, biodegradation. This supports the possibility of synthesis of LDPE/ Starch Blends from agro-waste products.

\section{ACKNOWLEDGMENT}

The authors acknowledged Covenant University for the financial support offered for the publication of this research.

\section{REFERENCES}

[1] Kühn, S., Rebolledo, E.L.B., van Franeker, J.A. (2015). Deleterious effects of litter on marine life. Marine Anthropogenic Litter, 75-116. https://doi.org/10.1007/978-3-319-16510-3_4

[2] Gaia, Europe, Z.W. (2018). Recycling is not enough. It's time to rethink how to solve the plastic waste crisis. https://www.no-burn.org/recyclingisnotenough/

[3] Shamsuddin, I.M., Jafar, J.A., Shawai, A.S.A., Yusuf, S., Lateefah, M., Aminu, I. (2017). Bioplastics as better alternative to petroplastics and their role in national 
sustainability: A review. Advances in Bioscience and Bioengineering, 5(4): 63-70. http://dx.doi.org/10.11648/j.abb.20170504.13

[4] Iles, A., Martin, A.N. (2013). Expanding bioplastics production: sustainable business innovation in the chemical industry. Journal of Cleaner Production, 45: 3849. https://doi.org/10.1016/j.jclepro.2012.05.008

[5] Tabone, M.D., Cregg, J.J., Beckman, E.J., Landis, A.E. (2010). Sustainability metrics: Life cycle assessment and green design in polymers. Environmental Science \& Technology, $\quad 44(21)$ : $\quad 8264-8269$. https://doi.org/10.1021/es101640n

[6] Abreu, A.S., Oliviera, M., De Sa, A., Rodrigues, R.M., Cerqueira, M.A., Vicente, A.A., Machado, A.V. (2015). Antimicrobial nanostructural starch based films for packaging. Carbohydrate Polymers, 129: 127-134. https://doi.org/10.1016/j.carbpol.2015.04.021

[7] Nagahata, Y., Koboyashi, M., Goto, Y., Inouchi, N. (2013). The formation of resistant starch during acid hyrolysis of high amylose corn starch. Journal of Applied Glycoscience, 60: 123-139. https://doi.org/10.5458/jag.jag.JAG-2012_008

[8] Shi, A., Li, D., Wang, L.J., Li, B.Z., Adhikari, B. (2011). Preparation of starch-based nanoparticles through high pressure homogenization and mini-emulsion crosslinking: Influence of various process parameters on particle size and stability. Carbohydrate Polymers, 83(4): 1604-1610.

https://doi.org/10.1016/j.carbpol.2010.10.011

[9] Aldao, D.C., Sarka, E., Ulbrich, P., Menš1'kova', E. (2018). Starch nanoparticles-two ways of their preparation. Czech Journal of Food Science, 36(2): 133138. https://doi.org/10.17221/371/2017-CJFS

[10] Galván, K.L.P., Cardoso, L.G., de Carvalho Alves, J., Salgado, M.J.G., Tavares, P.P.L.G., Nascimento, R.Q. da Silva, J.B.A., Druzian, J.I. (2019). Development of active biodegradable films: starch films incorporated with starch nanoparticles and oregano essential oil. Journal of Bioengineering and Technology Applied to Health, 2(3): 92-98. https://doi.org/10.34178/jbth.v2i3.77

[11] Damodaran, S., Parkin, K.L. (2017). Fennema's Food Chemistry. CRC Press.

[12] Schmidt, V.C.R., Bertib, F., Portob, L.M., Laurindo, J.B. (2013). Production of starch acetate films with addition of bacterial cellulose nanofibers. Chemical Engineering Transactions,

2251-2256.
http://dx.doi.org/10.3303/CET1332376

[13] de la Torre-Gutiérrez, L., Chel-Guerrero, L.A., BetancurAncona, D. (2008). Functional properties of square banana (Musa balbisiana) starch. Food Chemistry, 106(3): $1138-1144$ http://dx.doi.org/10.1016/j.foodchem.2007.07.044

[14] Singh, N., Kaur, M., Sandhu, K.S., Guraya, H.S. (2004). Physicochemical, thermal, morphological and pasting properties of starches from some Indian black gram (Phaseolus mungo L.) cultivars. Starch-Stärke, 56(11): 535-544.

[15] Nain, V., Kaur, M., Sandhu, K.S., Thory, R., Sinhmar, A. (2020). Development, characterization, and biocompatibility of zinc oxide coupled starch nanocomposites from different botanical sources. International Journal of Biological Macromolecules, 162: 24-30. https://doi.org/10.1016/j.ijbiomac.2020.06.125

[16] Sandhu, K.S., Singh, N., Malhi, N.S. (2005). Physicochemical and thermal properties of starches separated from corn produced from crosses of two germ pools. Food Chemistry, 89(4): 541-548. https://doi.org/10.1016/j.foodchem.2004.03.007

[17] Shiga, T.M., Lajolo, F.M. (2005). Cell wall polysaccharides of common beans (Phaseolus vulgaris L.) - composition and structure. Carbohydrate Polymers, 63(1): $1-12$. https://doi.org/10.1016/j.carbpol.2005.06.025

[18] Ambigaipalan, P., Hoover, R., Donner, E., Liu, Q., Jaiswal, S., Chibbar, R., Nantanga, K.K.M., Seetharaman, K. (2011). Structure of faba bean, black bean and pinto bean starches at different levels of granule organization and their physicochemical properties. Food Research International, $\quad 44(9)$ : 2962-2974. https://doi.org/10.1016/j.foodres.2011.07.006

[19] García-Padilla, A., Moreno-Sader, K.A., Realpe, A., Acevedo-Morantes, M., Soares, J.B.P. (2020). Evaluation of adsorption capacities of nanocomposites prepared from bean starch and montmorillonite. Sustainable Chemistry and Pharmacy, 17: 100292. https://doi.org/10.1016/j.scp.2020.100292

[20] Martínez-Preciado, A.H., Estrada-Girón, Y., GonzálezÁlvarez, A., Fernández, V.V.A., Macías, E.R., Soltero, J.F.A. (2012). Physicochemical, morphological and rheological properties of canned bean pastes "negro Queretaro" variety (Phaseolus vulgaris L.). Journal of Food Science and Technology, 51(9): 1795-1805. https://doi.org/10.1007/s13197-012-0737-5 